\title{
Anesthesia in a child with Mulvihill-Smith syndrome
}

\author{
M. Stevic $\cdot$ D. Simic $\cdot$ I. Milojevic
}

Received: 19 December 2012/Accepted: 20 July 2013/Published online: 3 August 2013

(C) Japanese Society of Anesthesiologists 2013

Keywords Mulvihill-Smith syndrome . Anesthesia $\cdot$ Child $\cdot$ Diabetes mellitus

To the Editor:

Mulvihill-Smith syndrome (MSS) is a very rare disease with important anesthetic implications [1]. It is characterized by a short stature, senile face, small mouth opening, prognatio mandible, and atherosclerosis. This case illustrates the potential difficulties in airway management during major surgery in a child with MSS.

We report a case of a 10-year-old female child with MSS and diabetes mellitus type 2 who underwent general anesthesia for hepatic tumor extraction. Mallampaty score was III with Cormarck-Lehane gradus 3. Neck extension was limited, and she had a small mouth opening.

After premedication with atropine and midazolam, induction in anesthesia was performed with fentanyl, propofol, and vecuronium. We had some difficulties with mask ventilation, but we intubated the patient with a no. 1 Macintosh blade and orotracheal tube no. 4, 5, after the third attempt. A fiberoptic laryngoscope was available in the operating room.

There are not many papers that discuss anesthetic management in patients with progeria. Establishing the airway is one of the problems, including a difficult airway with small mouth opening [2]. The anesthetic management and positioning of these patients may be difficult because of atherosclerosis, bone deformities, and arthritic changes of the joints [3,4]. The anesthetic management was planned as if this patient were a geriatric case because these patients have physiological changes suggestive of old age despite being chronologically and psychologically young [3].

Although there were no complications in establishing the airway in our case, it is important to evaluate the airway before the induction of anesthesia and to be prepared for difficult airway management.

Conflict of interest None.

\section{References}

1. Kuribayashi J, Yamada T, Morisaki H, Takeda J. Anesthetic management of a patient with Mulvihill-Smith syndrome. Masui. 2007;56(7):835-7 (abstract).

2. American Society of Anesthesiologists Task Force on Management of the Difficult Airway. Practice guidelines for management of the difficult airway: an updated report by the American Society of Anesthesiologists Task Force on Management of the Difficult Airway. Anesthesiology. 2003;98:1269-77.

3. Menna R, Arancibias C. The Hutchinson-Gilford progeria syndrome: a case report. Minerva Anestesiol. 2010;76:151-4.

4. Nguyen N, Mayhew J. Anaesthesia for a child with progeria. Pediatr Anaesth. 2001;11(3):370-1. 